\title{
Homicídios em Alagoas: desafios e evidências empíricas ${ }^{1}$
}

\author{
Emerson do Nascimento \\ Júlio Cezar Gaudêncio
}

Resumo: Alagoas é o estado que registrou o maior número de homicídios no ano passado, segundo a sexta edição do Anuário Brasileiro de Segurança Pública divulgado em novembro de 2013. Foram registradas 74,5 mortes para cada grupo de 100 mil habitantes no estado, o que representa aumento de 9,3\% em relação a 2010. Nos últimos 10 anos, a violência cresceu $117 \%$ em no estado de Alagoas e, pela segunda vez consecutiva, Maceió continua a ser a capital com maior taxa de homicídios. O objetivo deste artigo é abordar de forma preliminar as interconexões entre crime e cidade no estado de Alagoas a partir dos dados e indicadores necessários para a compreensão dessas dimensões.

Palavras-chave: Homicídios, crime, cidade.

\begin{abstract}
Alagoas is the state that recorded the highest number of homicides last year, according to the sixth edition of the Brazilian Yearbook of Public Safety released in November 2013. 74.5 deaths were recorded for every 100 thousand inhabitants in the state, which represents an increase of $9.3 \%$ over 2010 . Over the past 10 years, the violence has grown $117 \%$ in the state of Alagoas and for the second consecutive time, Maceio remains the capital with the highest homicide rate. The purpose of this article is to address in a preliminary way the interconnections between crime and city in the state of Alagoas from data and indicators needed to understand these dimensions.
\end{abstract}

Key words: Homicides, crimes, city.

\section{APRESENTAÇÃO}

\footnotetext{
${ }^{1}$ Este artigo é parte de uma pesquisa maior intitulada A Dinâmica dos Padrões de Homicídio em Alagoas: Maceió e Região Metropolitana, desenvolvida junto ao Instituto de Ciências Sociais da Universidade Federal de Alagoas e conta com a parceira e colaboração da Secretaria de Estado de Defesa Social do Estado de Alagoas (SEDS) e o apoio do CNPq. É fundamental, portanto, registrar nossos agradecimentos à colaboração do Capitão Anderson Cabral Tavares de Lima, a Flávio Azevêdo de Omena e aos alunos Helder Vasconcelos Neto e Anna Virgínia Cardoso da Silva.
}

Latitude, Vol. 7, no 2, pp. 109-132, 2013 
Homicídios em Alagoas: desafios e evidências empíricas

O Brasil é um dos países mais violentos do mundo, ocupando hoje a sétima posição segundo ranking promovido pela Organização Mundial da Saúde (OMS). A cada 100 mil habitantes, 27,4 são vítimas de crimes no Brasil. No caso de jovens entre 14 e 25 anos, o número aumenta para 54,8. De acordo com os dados oferecidos pela OMS, todos os 10 países com mais altas taxas de homicídios ${ }^{2}$ entre jovens estão na região da América Latina e do Caribe. O primeiro lugar é liderado por El Salvador, depois Ilhas Virgens, Trinidad e Tobago, Venezuela, Colômbia, Guatemala, Brasil, Panamá, Porto Rico e Bahamas. Tratando-se do caso de homicídios de jovens no Brasil, nossas taxas são 500 vezes maiores do que Hong Kong, 273 vezes maior do que a Inglaterra e o Japão e 137 vezes maior do que a Alemanha e a Áustria ${ }^{3}$.

Propor um debate sobre homicídios significa admitir, desde já, a urgência dessa questão como legítima demanda social. Em Alagoas, o tema da segurança pública é hoje um dos aspectos chaves da questão social que se torna cada vez mais complexa. Nos últimos anos, o quadro trágico da violência no estado, em particular os homicídios, tem ganhado destaque nos noticiários locais e nacionais, suscitando polêmicas nos meios acadêmicos e diferentes reações na sociedade alagoana. Para dar conta do fenômeno, reformulam-se antigos conceitos ou forjam-se novos, antes mesmo de se conseguir precisar os impactos dessa violência letal ou conhecer as reais dimensões da sua escalada.

Os índices de violência no estado, especialmente homicídios, vêm aumentando de forma vertiginosa desde o final dos anos $90^{4}$. Segundo relatório da Unesco com

\footnotetext{
${ }^{2}$ A taxa de homicídio é um indicador apropriado para comparar o nível de homicídios de uma localidade com outra, uma vez que seria inútil comparar o número de homicídios de cidades ou regiões com densidades populacionais diferentes. Neste sentido, a elevação da taxa de mortalidade específica de uma dada localidade significa que a violência letal de uma determinada área está aumentando.

${ }^{3} \mathrm{O}$ Brasil tem também uma enorme população carcerária. Para cada 500 habitantes no Brasil existe uma pessoa presa. Essa taxa só é inferior à dos Estados Unidos e da Rússia, segundo dados do Internacional Center for Prision Studies, citados pela revista The Economist (2010). O gasto público com segurança pública das três esferas de governo alcança atualmente 2,5\% do PIB (segundo dados da Secretaria do Tesouro Nacional de 2009), ou seja, se gasta com segurança pública no Brasil, metade do que se gasta com educação. Esse percentual era de $1 \%$ em 2000, isso quer dizer que ao longo da última década os gastos mais que dobraram e os resultados não melhoraram.

${ }^{4}$ A partir de 1999, em Maceió, a violência (em termos de homicídios) aumentou de maneira significativa. Neste ano, a capital do estado registrou uma taxa de homicídios para cada 100 mil habitantes de 30,9, passando para 98 em 2006, segundo dados do Ministério da Saúde e do Ipeadata. Este crescimento na taxa de homicídios pode ser percebido em função do título que a capital acabou por receber - a capital mais violenta do Brasil -, tendo em vista que Maceió
} 
dados do período de 1989-98, Alagoas figura entre os estados brasileiros com maior incidência de homicídios entre a população em geral e entre os jovens. A análise da dinâmica dos homicídios, com base em séries históricas, as formas de enfrentamento do problema, tanto no plano individual e coletivo quanto no plano político e institucional, as ações do crime organizado, a impunidade, tudo isso indica que o seu impacto vai além das estatísticas dos casos registrados, daí a sua singularidade em relação aos outros tipos de violência.

Causa indignação a cruel constatação - já registrada nos relatórios do Sistema de Informações sobre Mortalidade, do Ministério da Saúde - de que as estatísticas sobre mortalidade continuam exibindo números alarmantes de homicídios. Qualquer tentativa de definir melhor a dinâmica dos homicídios em Alagoas torna-se provisória ou inviável do ponto de vista teórico e prático sem antes considerar o emaranhado de fatos que caracterizam aquele contexto ao longo do tempo, especialmente o cenário descontrolado a partir do final da década de 90.

\section{OS ESTUDOS SOBRE PADRÕES DE HOMICÍDIOS}

A violência urbana aparece hoje como um dos principais problemas enfrentados, seja pela população de maneira geral, seja por parte dos gestores públicos. Não obstante, a grande maioria destes percentuais concentram-se nas regiões metropolitanas de algumas capitais brasileiras, com crescente destaque para o crescimento destes percentuais no Nordeste do Brasil. Além de toda a sensação de insegurança que toma a sociedade civil e a mídia, e de todo o terror social que pode daí emergir, há um tipo de indicador deveras concreto, adequado e perfeitamente comparável para avaliar a dimensão dessa violência urbana: o crime de homicídio.

Não desprezamos o reconhecimento de que esta não é a única forma de violência possível, é claro; todavia, acreditamos que seja este o indicador mais seguro para mensurar a dimensão dessa violência urbana, tendo em vista que as ocorrências de criminalidade despertam não só uma reação moral e institucional, mas também são menos passíveis a subnotificação, sobretudo quando pensamos em outros tipos de violências como: estupros, agressões físicas não letais ou crimes contra o patrimônio. Nesse sentido, é este indicador que utilizaremos aqui para refletir sobre a violência urbana no estado de Alagoas, especialmente na Região Metropolitana de Maceiós,

passou a ocupar posição de destaque no ranking de homicídios das capitais brasileiras (Cerqueira, 2013).

${ }^{5}$ De acordo com a Lei Complementar $n^{\circ} 18$ de 19 de novembro de 1998, que dispõe sobre a criação da Região Metropolitana de Maceió, a mesma é composta pelos seguintes municípios:

Latitude, Vol. 7, nº 2, pp. 109-132, 2013

DOI: https://doi.org/10.28998/2179-5428.20130207 
Homicídios em Alagoas: desafios e evidências empíricas

utilizando prioritariamente dados do Sistema de Informação de Mortalidade (SIM) do Ministério da Saúde (MS), dados de população do Instituto Brasileiro de Geografia e Estatística (IBGE) e dados da Secretaria de Estado de Defesa Social de Alagoas (SEDS$\mathrm{AL})$.

Tal como qualquer outra ação humana, a violência física tem uma história. Para boa parte da literatura de orientação sócio histórica, a violência aberta, resultado das manifestações emocionais humanas não controladas, foi paulatinamente sendo controlada e/ou moldada a partir da formação do Estado Moderno e do progresso do processo civilizador, seja através do entendimento da ideia de que somente o Estado deve exercer o direito legítimo à força, seja a partir de uma sublimação da agressividade através dos hábitos, dos costumes, dos gestos ou mesmo da educação ${ }^{6}$.

Vários estudos clássicos europeus ${ }^{7}$ sobre homicídios que contemplam largos períodos comprovam as teses de Elias e Foucault do autocontrole e da redução da violência na sociedade moderna. Um indicador importante destes estudos é o entendimento da importância da cidade como um espaço privilegiado da regulação racional do Estado e do exercício dos direitos de cidadania. Nesse sentido, não parece contraditório que hoje presenciemos a explosão de índices alarmantes de homicídios exatamente nos grandes centros urbanos? A partir de que momento e por que as cidades deixam de ser palco privilegiado do controle dessa agressividade homicida?

Acreditamos que a resposta para esse enigma repousa sobre a relação entre organização social do espaço urbano e criminalidade violenta. Compreendemos que a cidade continua sendo um espaço privilegiado desde o advento da Modernidade, todavia, apontamos para a forma como se dá o processo de modernização e urbanização desses grandes centros. Em outras palavras, é de fundamental importância interseccionar os indicadores dessa violência homicida com outras taxas referentes a grau de urbanização; migração rural-urbana e seu impacto sobre a economia local; densidade populacional; incapacidade do Estado de prover serviços sociais básicos como saúde, educação, transporte público; segregação urbana e apartheid social; pobreza e desigualdade; crime organizado e tráfico de drogas - ou seja, é preciso explicar como e por que o controle social foi perdido ou enfraquecido nestes grandes centros urbanos.

Maceió, Rio Largo, Satuba, Santa Luzia do Norte, Coqueiro Seco, Messias, Paripueira, Barra de Santo Antônio, Barra de São Miguel, Marechal Deodoro e Pilar.

${ }^{6}$ Sobre a ideia do Estado como proprietário do poder legítimo da força Cf. Weber, 1981. Sobre a sublimação da agressividade pela via do processo civilizar ou pela educação Cf. Elias, 2011a, 2011b; Foucault, 2006.

${ }^{7}$ Cf. Eisner, 2001; Spierenburg, 1996. 
Desde a publicação de Patterns of Criminal Homicides, a maioria dos estudos sobre padrões de homicídios adere a abordagens baseadas também em múltiplos fatores. Pesquisas que seguem essa tradição descrevem a distribuição sócio demográfica tanto quanto a dinâmica espacial e temporal da violência letal, mas apenas num sentido muito limitado podem ser consideradas como capazes de fornecer explicações. Descrevem mais que explicam o que ocorre numa população específica ao produzirem um perfil detalhado e desagregado do problema do homicídio. Pesquisas desse tipo são úteis como um primeiro passo para o desenvolvimento de abordagens mais aprofundadas, que possam produzir resultados teóricos relevantes sobre as causas dos homicídios, todavia, carecem de aprofundamento.

Talvez o candidato mais conhecido para principal referência europeia clássica nos estudos sobre homicídios seja o acadêmico finlandês Veli Verkko. De 1920 a 1950, ele publicou muitos estudos que combinavam forte base empírica com a preocupação na identificação de padrões gerais e características invariantes da violência letal. Atualmente ele é conhecido como o autor das chamadas "leis de Verkko" ${ }^{\text {. }}$ Uma das observações importantes das pesquisas de Verkko que, exageradamente chamou-as de "leis", é a de que a proporção de vítimas femininas de homicídio é mais alta quanto mais baixa for a taxa geral de homicídios, e vice-versa. Essa correlação observada é ainda válida. Desde então, muitos estudos tem buscado padrões nos homicídios ${ }^{10}$, mas as especificidades históricas e societárias tendem a produzir variações importantes, o que justifica pesquisas sobre fatores que se associam em incidências exclusivamente locais ${ }^{11}$.

Os principais estudos sobre padrões de homicídios no Brasil são recentes. Além dos estudos publicados em periódicos especializados, três livros e duas teses reúnem as principais contribuições até agora ${ }^{12}$. No plano analítico são conhecidos os trabalhos que relacionam homicídios e tráfico de drogas ${ }^{13}$. No estado de Alagoas, há despeito dos vários e importantes estudos já realizados ${ }^{14} \mathrm{e}$ das altas taxas de violência letal apresentadas, ainda não há trabalhos deste tipo. Nesse sentido, neste momento, o que apresentaremos é o resultado corrente de nossas pesquisas em andamento: a caracterização do fenômeno da violência homicida em Alagoas.

\footnotetext{
${ }^{8}$ Cf. Wolfgang, 1958.

${ }^{9}$ Cf. Verkko, 1951.

${ }^{10}$ Cf. Liem \& Pridemore, 2012; Eisner, 2009; Messner \& Rosenfeld, 1997.

${ }^{11} \mathrm{Cf}$. Monkkonen, 2006.

${ }^{12}$ Cf. Cruz \& Batitucci (Org.). 2007; Soares, 2008; Beato, 2012; Cerqueira, 2010; Manso, 2012.

${ }^{13}$ Cf. Zaluar, 1994; Misse, 2006.

${ }^{14}$ Cf. Vasconcelos \& Pimentel, 2011; 2009.
}

Latitude, Vol. 7, no 2, pp. 109-132, 2013 
Homicídios em Alagoas: desafios e evidências empíricas

\section{CARACTERIZAÇÃO GERAL DOS HOMICÍDIOS EM ALAGOAS}

Este artigo abordará de forma preliminar as interconexões entre crime e cidade no estado de Alagoas a partir dos dados e indicadores necessários para a compreensão dessas dimensões. Nesse sentido, serão exploradas as taxas de homicídio e sua relação com a dinâmica contextual das comunidades urbanas da capital e da região metropolitana do estado ${ }^{15}$, visando esmiuçar e desagregar territorialmente e temporalmente essas dimensões. Nos interessa neste momento, averiguar em qual local exato se deram os incidentes criminais, a que horas e qual o sexo, faixa etária das vítimas, qual o principal tipo de arma (se utilizada) nestas ocorrências. Diante das dificuldades de condensar mapas e bancos, muitas vezes registrados a partir de perspectivas institucionais e/ou particulares diferentes, tentamos de forma exploratória montar o quebra-cabeça da violência em Alagoas a partir daquelas que devam ser as melhores informações disponíveis, a saber: os dados oferecidos por instituições públicas de pesquisa e gestão de Estado, tanto federais, quanto estaduais.

Alagoas é o estado que registrou o maior número de homicídios no ano passado, segundo a sétima edição do Anuário Brasileiro de Segurança Pública ${ }^{16}$ divulgada em outubro do ano passado pelo Fórum Brasileiro de Segurança Pública $(\mathrm{FBSP})^{17}$. Foram registradas 61,8 mortes para cada grupo de 100 mil habitantes ${ }^{18}$, o que

\footnotetext{
${ }^{15}$ Neste artigo utilizamos dados do Sistema Nacional de Estatísticas em Segurança Pública e Justiça Criminal (SINESPJC); Secretaria Nacional de Segurança Pública (SENASP); Fórum Brasileiro de Segurança Pública (FBSP); Ministério da Saúde/Sistema de Informação de Mortalidade (MS/SIM); Secretaria de Estado de Defesa Social de Alagoas (SEDS-AL); Ministério da Fazenda (MF) e do Instituto Brasileiro de Geografia e Estatística/Pesquisa Nacional por Amostra de Domicílios (IBGE/PNAD).

${ }^{16} \mathrm{O}$ anuário reúne dados dos órgãos de segurança pública dos estados e do governo federal, além de informações do Instituto Brasileiro de Geografia e Estatísticas (IBGE), do Ministério da Saúde e do próprio FBSP. Este ano, o documento dividiu os estados por categoria de qualidade da informação fornecida porque os sistemas de informação são abastecidos de forma diferenciada por cada unidade da federação.

${ }^{17}$ É importante realçar que, de acordo com o Anuário Brasileiro de Segurança Pública de 2013, Alagoas é não só o estado que apresenta as maiores taxas de homicídio, mas também um dos estados com as estatísticas criminais mais confiáveis para os últimos três anos, apresentando alta qualidade nas informações sobre homicídio e vitimização e no registro destas informações junto ao SINESPJC. Destaque nesse processo para o papel desempenhado pela Secretária de Defesa Social do Estado de Alagoas (SEDS-AL), que adotou a partir de 2011 um novo tipo de identificação do cadáver para casos de morte violenta, acidentais ou com suspeita de violência
} 
representa, a partir de números absolutos, o registro de pelo menos 5 crimes violentos letais intencionais por dia no estado durante o ano de 2012. O resultado repete, mais uma vez, o ranking do último levantamento, quando Alagoas também ficou em primeiro lugar, seguido por Pará e Ceará, que registraram, respectivamente, 44,6 e 42,5 mortes por 100 mil habitantes para o ano de 2012.

A violência tem se tornado um problema alarmante em Alagoas, atingindo o crescimento estratosférico de $117 \%$ nos últimos 10 anos e ocupando a posição de capital com a maior taxa de homicídios desde 2006. O Anuário Brasileiro de Segurança Pública revela ainda que a cidade mais violenta do estado é Pilar. No ranking nacional dos 100 municípios mais violentos, Pilar aparece na $5^{\mathfrak{a}}$ posição. Logo abaixo são citados mais oito cidades alagoanas: Maceió $\left(8^{\circ}\right)$, Arapiraca $\left(20^{\circ}\right)$, Rio Largo (32ํ), Marechal

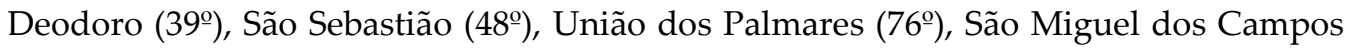
$\left(81^{\circ}\right)$ e Messias $\left(100^{\circ}\right)^{19}$.

\begin{tabular}{lcccc}
\hline \multicolumn{5}{c}{ TABELA 1: ORDENAMENTO DAS CAPITAIS } \\
\multicolumn{4}{c}{ BRASILEIRAS POR TAXA DE HOMICÍDIO } & $(\mathbf{2 0 0 0 - 2 0 1 0 )}$ \\
\hline Capital & 2000 & Posição & 2010 & Posição 2 \\
\hline Maceió & 45,1 & $8^{\underline{a}}$ & 109,9 & $1^{\underline{a}}$ \\
João Pessoa & 37,8 & $13^{\underline{a}}$ & 80,3 & $2^{\underline{a}}$ \\
Vitória & 79 & $2^{\underline{a}}$ & 67,1 & $3^{\underline{a}}$ \\
Recife & 97,5 & $1^{\underline{a}}$ & 57,9 & $4^{\underline{a}}$ \\
São Luís & 16,6 & $24^{\underline{a}}$ & 56,1 & $5^{\underline{a}}$ \\
Curitiba & 26,2 & $20^{\underline{a}}$ & 55,9 & $6^{\underline{a}}$ \\
Salvador & 12,9 & $25^{\underline{a}}$ & 55,5 & $7^{\underline{a}}$ \\
Belém & 25,9 & $2^{\underline{a}}$ & 54,5 & $8^{\underline{a}}$ \\
Porto Velho & 61 & $5^{\underline{a}}$ & 49,7 & $9^{\underline{a}}$ \\
& & & &
\end{tabular}

(mortes a esclarecer), a saber: a chamada Pulseira de Identificação do cadáver (PIC), a qual possui um número a ser anotado tanto na Declaração de Óbito, quanto no Registro de Ocorrência. Embora simples, esse procedimento representou um salto qualitativo no tratamento destes dados, resolvendo alguns problemas relacionados ao fluxo de informações sobre homicídios, como por exemplo, a criação de um recurso de convergência das informações e até mesmo o impedimento de registro duplicados de um mesmo homicídio, o que não era incomum antes destas mudanças (Borges, 2013).

${ }^{18}$ Os índices recomendados pela Organização das Nações Unidas (ONU) prevê o máximo de 10 homicídios anuais por 100 mil habitantes.

${ }^{19}$ Para o ranking das cidades mais violentas conferir: WAISELFISZ, 2012. 
Homicídios em Alagoas: desafios e evidências empíricas

\begin{tabular}{|c|c|c|c|c|}
\hline Macapá & 46,2 & $7^{\underline{a}}$ & 49 & $10^{\mathrm{a}}$ \\
\hline Manaus & 33 & $17^{\mathrm{a}}$ & 46,7 & $11^{\mathrm{a}}$ \\
\hline Fortaleza & 28,2 & $19^{a}$ & 45,9 & $12^{\mathrm{a}}$ \\
\hline Aracaju & 39,9 & $10^{\mathrm{a}}$ & 42 & $13^{a}$ \\
\hline Cuiabá & 69,5 & $3^{\mathrm{a}}$ & 40,1 & $14^{\mathrm{a}}$ \\
\hline Goiânia & 28,6 & $18^{\mathrm{a}}$ & 39,8 & $15^{\mathrm{a}}$ \\
\hline Porto Alegre & 39,2 & $12^{\mathrm{a}}$ & 36,8 & $16^{\mathrm{a}}$ \\
\hline \multicolumn{5}{|l|}{ Belo } \\
\hline Horizonte & 34,8 & $16^{\mathrm{a}}$ & 34,9 & $17^{\mathrm{a}}$ \\
\hline Brasília & 37,5 & $14^{\mathrm{a}}$ & 34,2 & $18^{\mathrm{a}}$ \\
\hline Natal & 10,4 & $26^{\mathrm{a}}$ & 32,3 & $19^{a}$ \\
\hline Teresina & 22,2 & $22^{\mathrm{a}}$ & 30,8 & $20^{a}$ \\
\hline Boa Vista & 40,4 & $9^{\mathrm{a}}$ & 28,5 & $21^{\mathrm{a}}$ \\
\hline Rio Branco & 36,4 & $15^{\mathrm{a}}$ & 25,9 & $22^{\mathrm{a}}$ \\
\hline $\begin{array}{l}\text { Rio de } \\
\text { Janeiro }\end{array}$ & 56,6 & $6^{\mathrm{a}}$ & 24,3 & $23^{\circ}$ \\
\hline Florianópolis & 10,2 & $27^{a}$ & 22,8 & $24^{\mathrm{a}}$ \\
\hline Palmas & 21,8 & $23^{\underline{a}}$ & 22,3 & $25^{\mathrm{a}}$ \\
\hline $\begin{array}{l}\text { Campo } \\
\text { Grande }\end{array}$ & 39,3 & $11^{\mathrm{a}}$ & 21,7 & $26^{\mathrm{a}}$ \\
\hline São Paulo & 64,8 & $4^{\mathrm{a}}$ & 13 & $27^{\mathrm{a}}$ \\
\hline
\end{tabular}

Fonte: MS/SIM

Elaboração dos autores.

Nota: taxa por 100 mil habitantes.

Em Alagoas, a dinâmica dos homicídios extrapola o que é prescrito pelo cenário nacional e regional, destacando-se principalmente pelas altas taxas de ocorrências e pelas singularidades perversas da vitimização. Em 1999, Maceió era a 14 a capital mais violenta do Brasil, atingindo o título macabro de capital mais violenta, pela primeira vez, a partir de 2006 e chegando ao expoente máximo desta violência homicida em 2010, quando foi registrado uma taxa de homicídios de 110,1 para cada 100 mil habitantes em Maceió. Apesar de alarmantes, estes dados são relativamente novos, visto que desde 1980 esta taxa situava-se no patamar de 25 homicídios por 100 mil habitantes, crescendo de forma drástica no fim dos idos de 1990. Contudo, é 
incorreto dizer que Alagoas seja o líder em violência letal quando consideradas outras taxas de mortalidade como os suicídios e os acidentes de trânsito.

O gráfico 1 mostra que as taxas de acidentes de trânsito, homicídios e suicídios no Brasil para os anos de 2006 a 2011 giram em torno de 20, 26 e 5, respectivamente, para cada grupo de 100 mil habitantes. Os gráficos 2 e 3 mostram que as taxas para as variáveis acidentes de trânsito e suicídios no Nordeste e em Alagoas são relativamente similares ao padrão nacional. Alagoas só destoa sensivelmente do padrão nacional e regional no que compreende especificamente a taxa de homicídios.

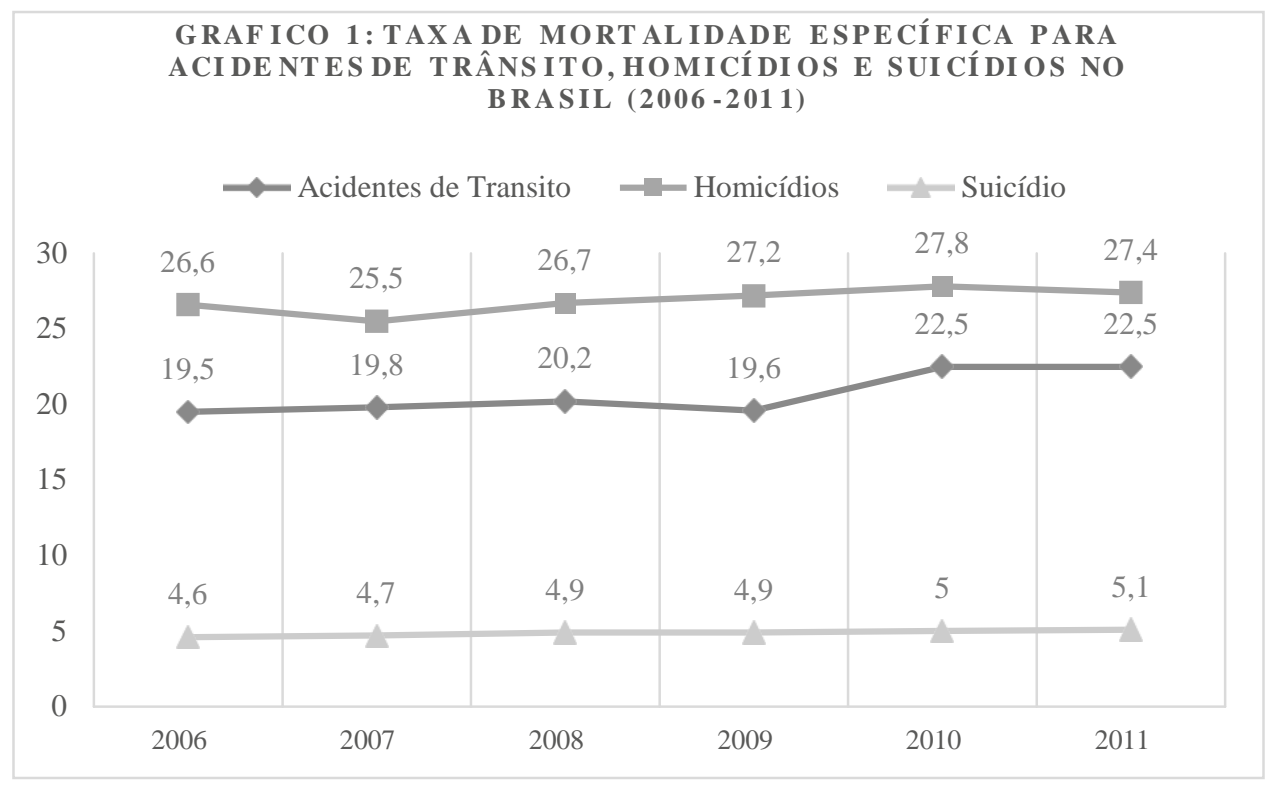

Fonte: MS/SIM

Elaboração dos autores.

Nota: taxa por 100 mil habitantes. 
Homicídios em Alagoas: desafios e evidências empíricas

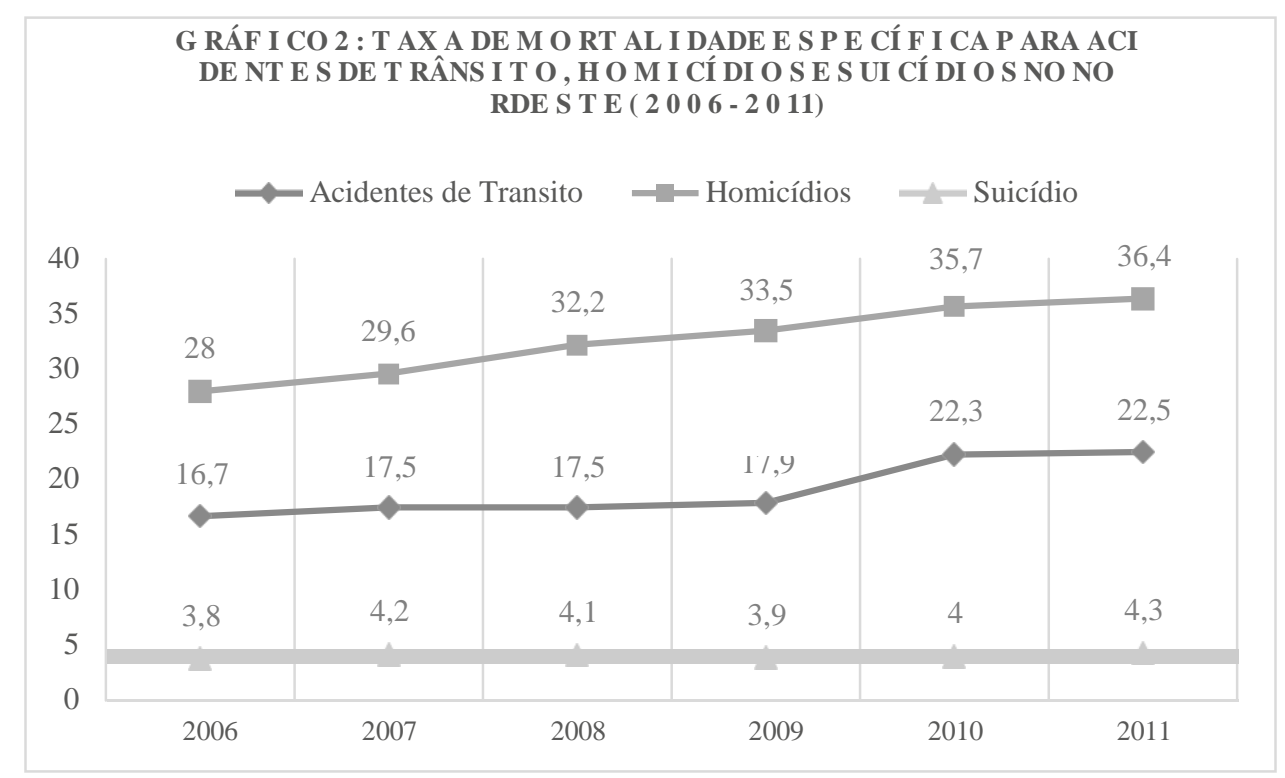

Fonte: MS/SIM

Elaboração dos autores.

Nota: taxa por 100 mil habitantes

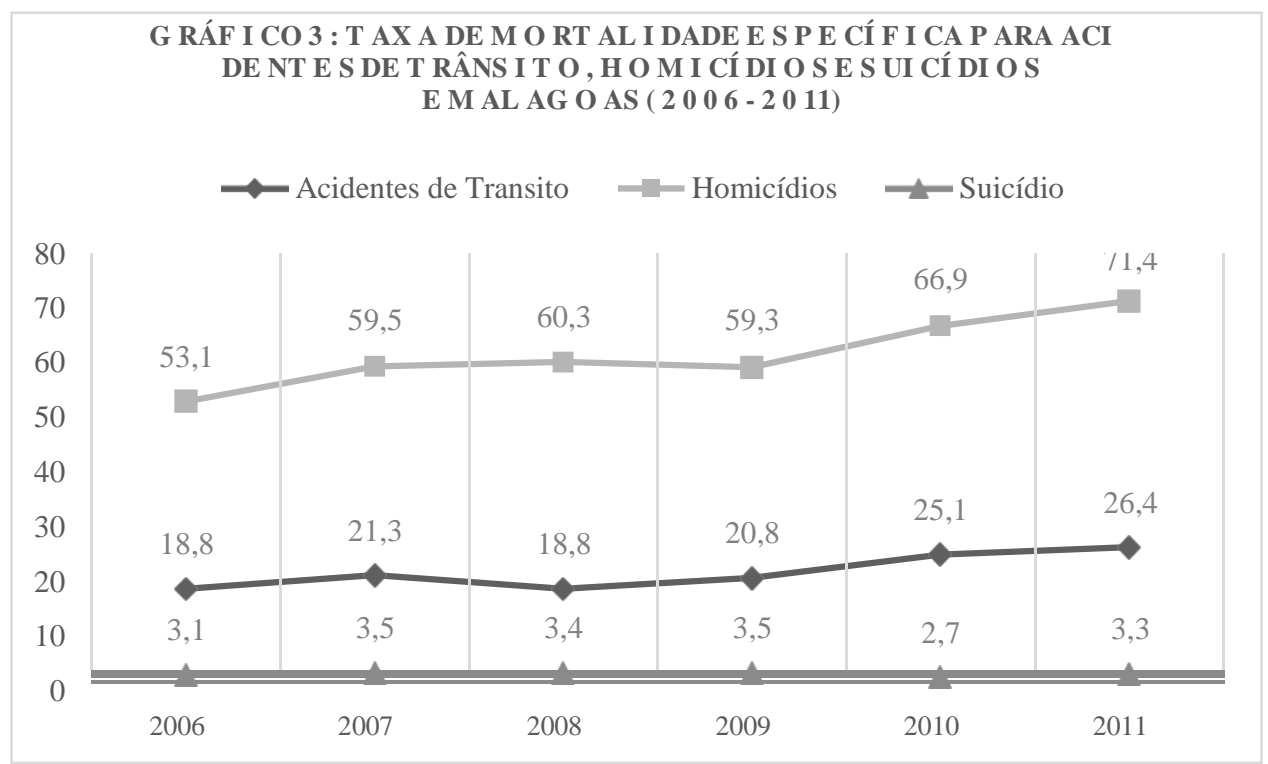

Fonte: MS/SIM 
Elaboração dos autores.

Nota: taxa por 100 mil habitantes

Em termos de violência letal, Alagoas e a Região Metropolitana de Maceió destoam da média brasileira apenas no registro dos incidentes que envolvem homicídios, que é o foco da nossa atenção neste presente momento. Nos gráficos 4 e 5 apresentamos as taxas de mortalidade específica para homicídios na Região Metropolitana (RM) de Maceió e a capital isoladamente.

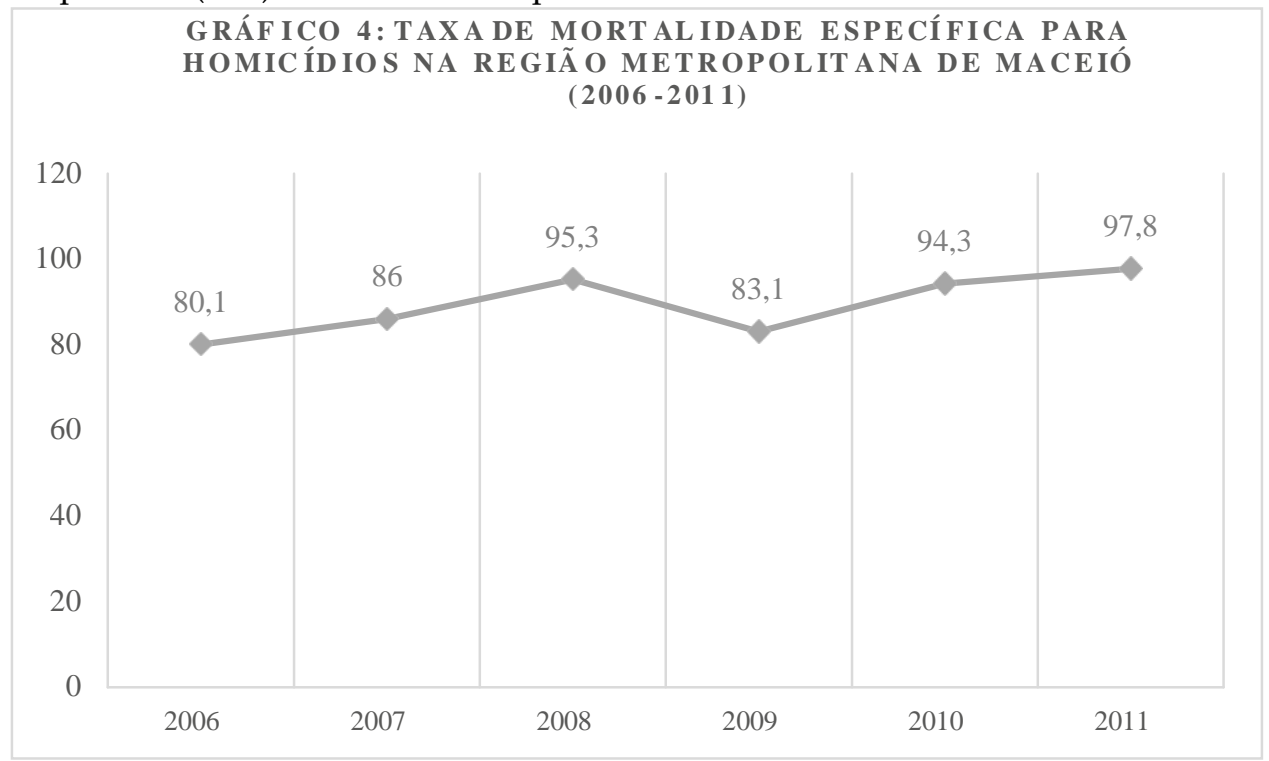

Fonte: MS/SIM

Elaboração dos autores.

Nota: taxa por 100 mil habitantes 
Homicídios em Alagoas: desafios e evidências empíricas

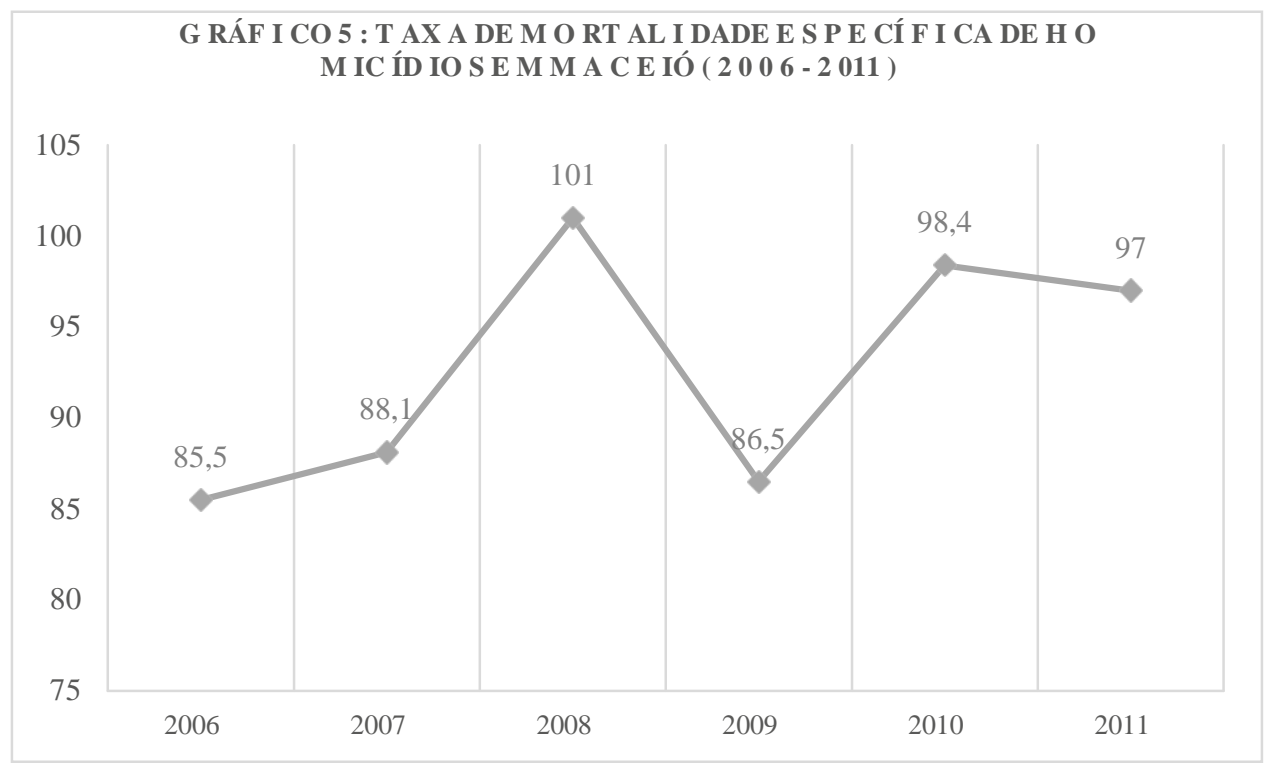

Fonte: MS/SIM

Elaboração dos autores.

Nota: taxa por 100 mil habitantes

Quanto ao número de óbitos por homicídio segundo local de residência, as taxas observadas referem-se principalmente à RM de Maceió, sendo o município de Pilar aquele que apresenta os maiores índices, inclusive entre os municípios brasileiros segundo dados do Instituto de Pesquisa Econômica Aplicada (IPEA). Em sequência, apresentamos o gráfico 6, onde comparamos as taxas de mortalidade específica para homicídios no Brasil, no Nordeste e na RM de Maceió no período que compreende 2006 a 2011. 


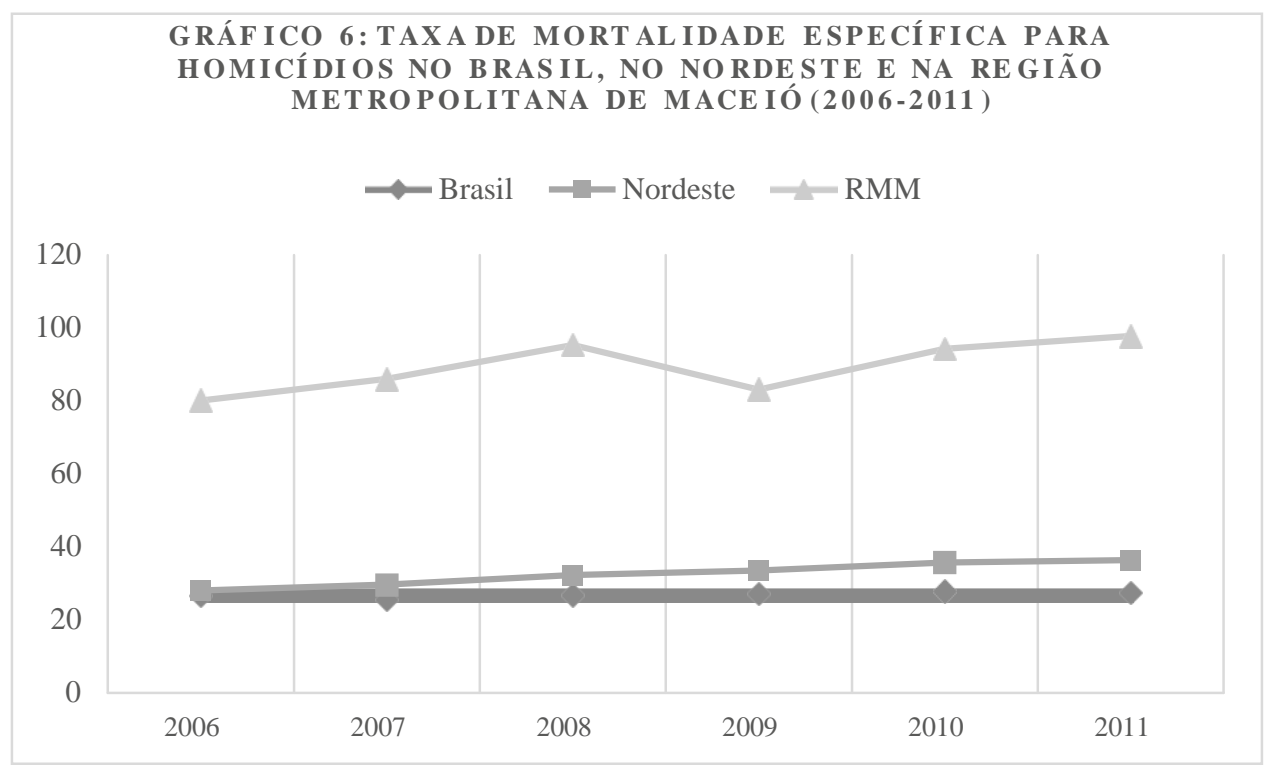

Fonte: MS/SIM

Elaboração dos autores.

Nota: taxa por 100 mil habitantes

Segundo dados da Secretaria de Estado de Defesa Social de Alagoas (SEDSAL), no ano de 2012, do total geral de 1.755 homicídios, 673 foram registrados na faixa etária dos 15 aos 24 anos. Os dados empíricos dos homicídios na capital, segundo grupos de sexo (gráfico 7), cor (gráfico 8) e idade (gráficos 9 e 10), confirmam as tendências do perfil nacional para essas categorias. As vítimas de homicídios são predominantemente homens, jovens - em torno de 20 anos de idade -, e de raça negra ou parda. 
Homicídios em Alagoas: desafios e evidências empíricas

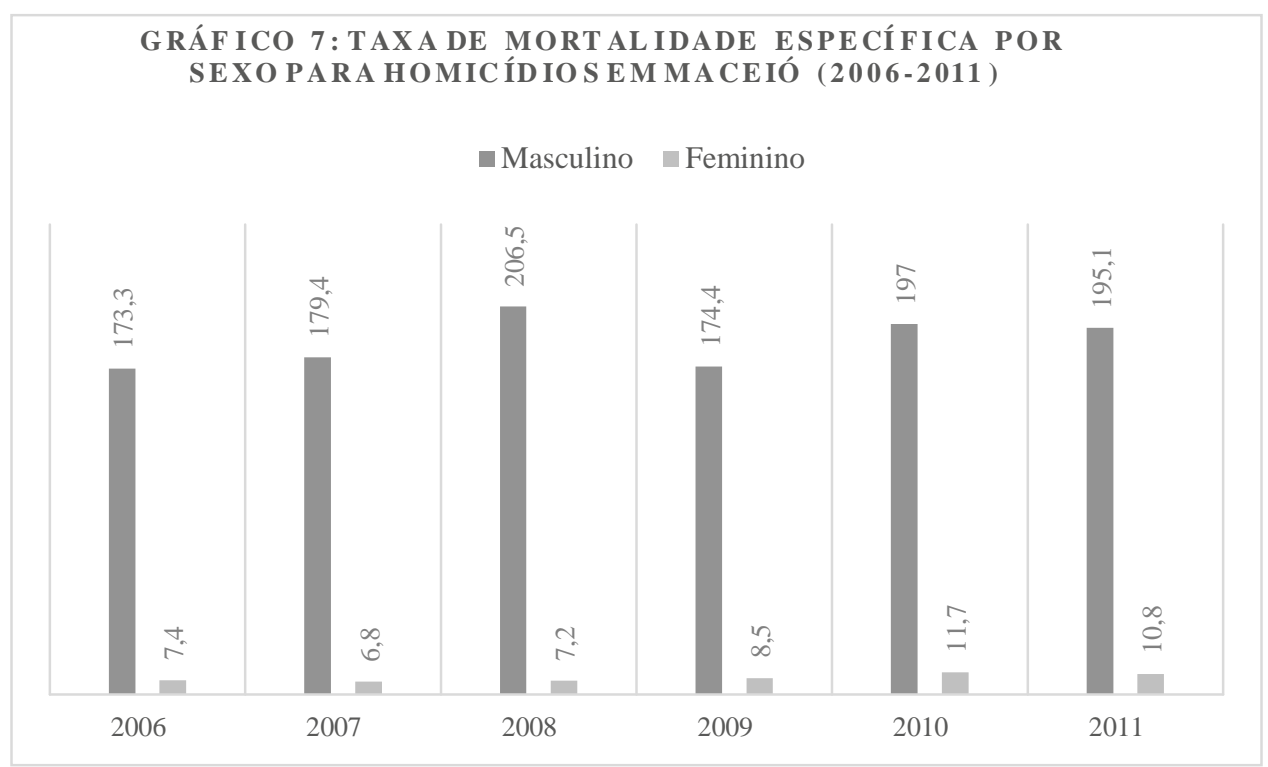

Fonte: MS/SIM

Elaboração dos autores.

Nota: taxa por 100 mil habitantes

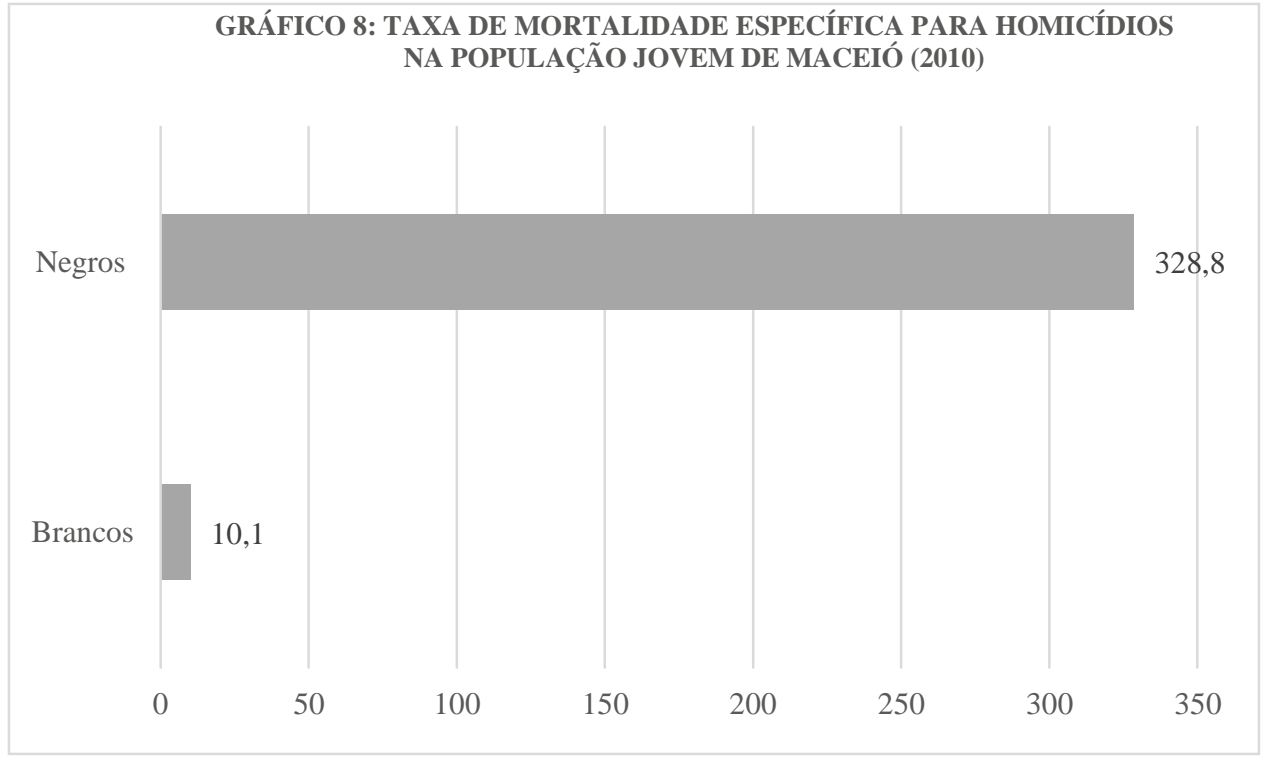

Fonte: MS/SIM; IBGE/PNAD

Elaboração dos autores. 
Nota: taxa por 100 mil habitantes

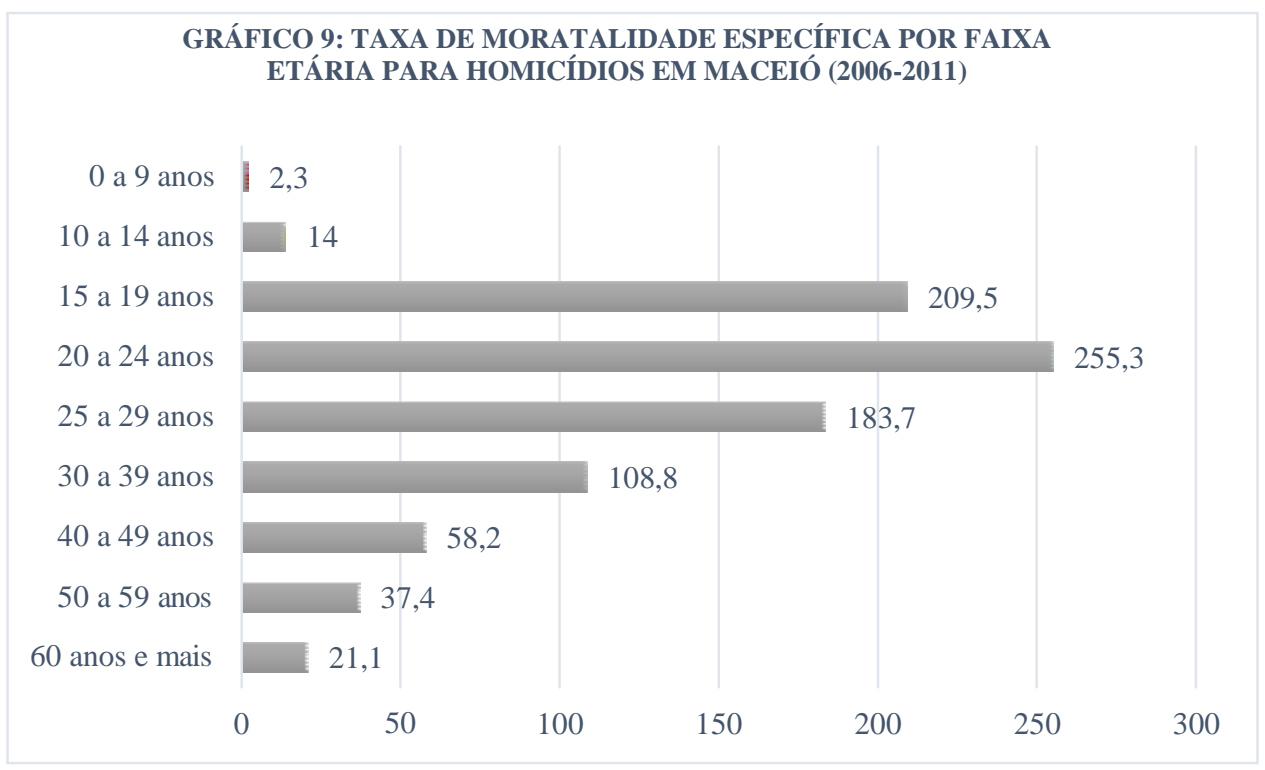

Fonte: MS/SIM; IBGE/PNAD

Elaboração dos autores.

Nota: taxa por 100 mil habitantes 
Homicídios em Alagoas: desafios e evidências empíricas

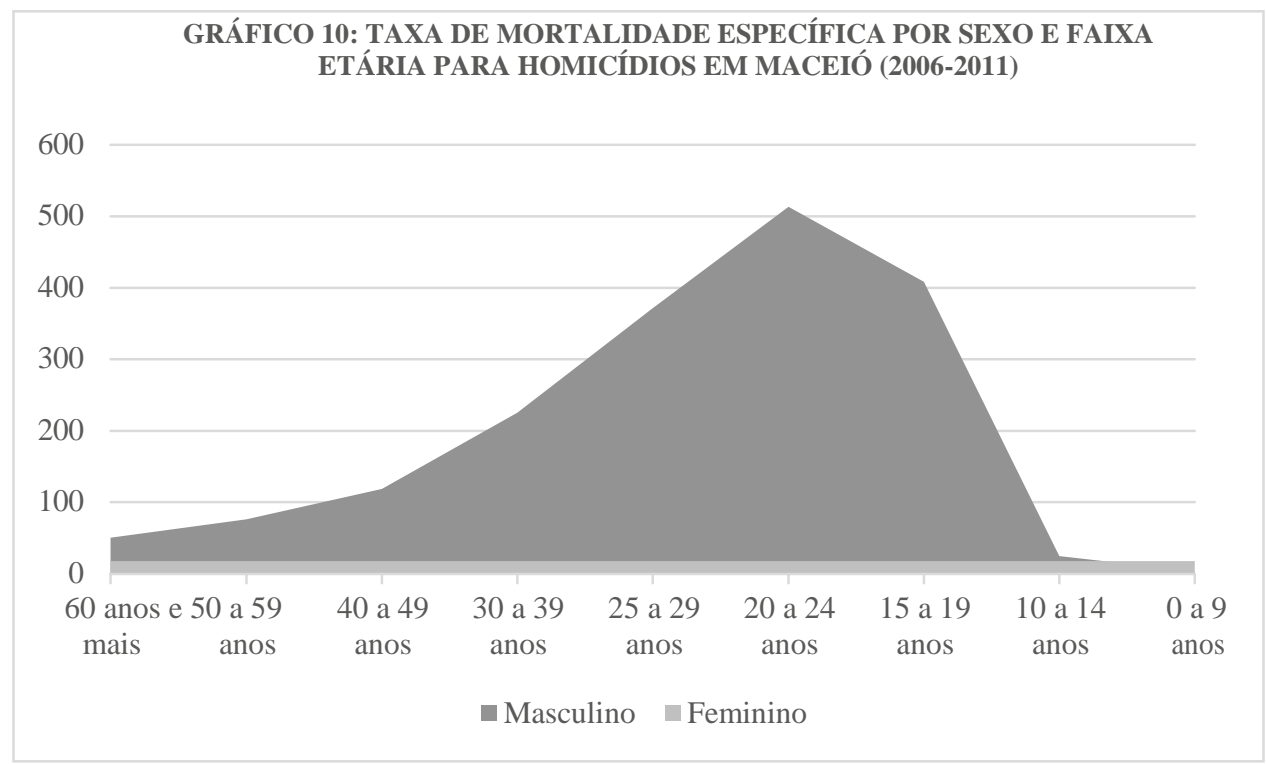

Fonte: MS/SIM; IBGE/PNAD

Elaboração dos autores.

Nota: taxa por 100 mil habitantes

Zanotelli (2003), com base nos estudos de Augustin Berque, ressalta a importância de se conhecer os territórios do crime, sua distribuição socioespacial, entendendo que há uma paisagem produzida localmente pela violência nestas aglomerações urbanas. Com relação aos elementos contextuais associados a esses homicídios em Alagoas, os dados disponíveis no Ministério da Saúde/Sistema de Informação de Mortalidade apontam para uma predominância destes incidentes na via pública, todavia dado o percentual de registro de homicídios que ocorreram em local desconhecido (87,9\%), a informação não parece ser muito segura ${ }^{20}$.

Quanto a temporalidade dos homicídios, a exemplo da tendência nacional, a maioria ocorre nos fins de semana, com uma evolução significativa dos casos a partir da sexta-feira. A relativa previsibilidade das ocorrências deve ser objeto de investigação, visando a adoção de medidas preventivas específicas de políticas

${ }^{20}$ Sobre a questão da localização exata dos incidentes de homicídio em Alagoas é importante realçar que muito em breve poderemos ter dados mais robustos sobre o item, pois a Secretaria de Estado de Defesa Social do Estado de Alagoas tem investido no georeferenciamento destas ocorrências. Muito em breve, teremos séries temporais maiores que poderão revelar tendência ou padrões mais constantes. 
públicas. Sabe-se, a partir dos bancos consultados, que a maior parte das ocorrências deram-se entre as 19 horas e as 22 horas, com maior prevalência para os dias de sábado e domingo, e que a arma de fogo foi o principal instrumento utilizado (pelo menos $82,2 \%$ dos casos) $)^{21}$.

No tocante a sazonalidade mensal, não se observa nenhuma tendência marcante no período analisado. De modo geral, registra-se um número elevado de óbitos em todos os meses do ano. Há pouca variação entre as diferentes estações do ano: a maior taxa foi no verão $(26,6 \%)$ e a menor no inverno $(23,6 \%)$; primavera e outono apresentam índices quase iguais (respectivamente $25,4 \%$ e $24,4 \%$ ).

A percepção de que os óbitos por homicídio constituem-se tão somente a partir de um conjunto de individualidades em interação é imperfeita a limita a compreensão do fenômeno como um todo relativamente homogêneo. A despeito das vicissitudes que explicam a "passagem ao ato", em situações que envolvem homicídios intencionais, os dados apontam para uma explosão da violência homicida no estado e revelam um padrão: em regra, as vítimas são jovens negros ou pardos, de estratos menos favorecidos, mortos por arma de fogo, geralmente à noite, em áreas circunspectas e nos horários e dias de maior interação social. Um elemento surpresa: embora faltem informações mais detalhadas sobre o algoz, índicos sugerem que o mesmo, em geral, possui um perfil bastante semelhante ao da vítima. Em outros termos, tratamos de uma "guerra" fraticida.

Nesse sentido, faz-se cada vez mais necessário pesquisas sobre a dinâmica dos referidos homicídios no estado de Alagoas, todavia, é necessário enriquecer estes dados não somente com a distribuição desigual de riscos no estado e/na capital, mas também, incorporar a estes indicadores as injustiças e desigualdades dos direitos econômicos, humanos e sociais na sociedade brasileira e na alagoana em particular. Os estudos sobre a dinâmica dos homicídios são essenciais tanto para o diagnóstico de tendências da criminalidade, quanto para a formulação (e subsequente monitoramento) de estratégias de controle e prevenção adequadas às particularidades locais e regionais ${ }^{22}$.

${ }^{21}$ Somente para o ano de 2013, em termos de números absolutos, a Secretaria de Estado de Defesa Social de Alagoas - SEDS, registrou o percentual de 79,69\% de crimes violentos letais intencionais praticados somente por arma de fogo e 1,77\% praticados por arma de fogo e arma branca. Dos homicídios ocorridos neste mesmo anos, 11,8\% foram praticados ainda somente por arma branca e $4,60 \%$ por espancamento.

${ }^{22}$ Segundo dados da Secretaria Estadual de Saúde, apresentam a incidência das maiores taxas de violência homicida no município de Maceió os bairros do Benedito Bentes, Jacintinho, Santa Lúcia, Tabuleiro dos Martins e Vergel. O mapeamento georeferenciado dos homicídios na capital alagoana e nas cidades com maior percentual de registro de violência homicida da RM

Latitude, Vol. 7, no 2, pp. 109-132, 2013 
Homicídios em Alagoas: desafios e evidências empíricas

\section{CARACTERIZAÇÃO DOS CRIMES NÃO LETAIS EM ALAGOAS}

É interessante observarmos que, tal como já mencionamos anteriormente, no que compreende às mortes causadas por fatores externos, Alagoas se diferencia exclusivamente da média nacional e regional no que diz respeito aos percentuais da violência homicida. Debruçando-se sobre o suplemento de violência da última Pesquisa Nacional por Amostra de Domicílios (PNAD/2009) ${ }^{23}$ do Instituto Brasileiro de Geografia e Estatística (IBGE), podemos verificar que o padrão de agressões físicas, furtos e roubos em Alagoas, comparado às demais Unidade da Federação, também não é significativo. Na verdade, Alagoas é o estado com menor prevalência de agressões físicas de todo o país $(0,9)$, o que revela uma realidade no mínimo paradoxal, quando comparamos às suas posições privilegiadas no ranking nacional da violência homicida.

Levando em conta que é significativa a probabilidade que um homicídio seja antecedido, pelo menos de uma agressão física, é curioso que a taxa destas ocorrências em Alagoas seja tão baixa. Indicadores dessa natureza nos faz crer menos na viabilidade da hipótese de que essa violência homicida seja explicada em função de uma cultura violenta própria ao estado como é fartamente realçado pela historiografia alagoana e pela mídia local. Não que Alagoas não seja conhecido, em um passado muito recente, pela prática desmedida da violência ligada à crimes políticos e de mando e à proliferação de grupos de extermínio, contudo, acreditamos que a violência que estudamos hoje e presenciamos na capital do estado e na RM transmutou-se em outra coisa. Tratamos de um fenômeno novo e diferente, onde a cultura explica parte, mas não o todo. Manter a mesma antiga hipótese para o fenômeno novo é preencher de vinho novo um odre já gasto - precisamos ir além.

segue em desenvolvimento em nossa pesquisa A Dinâmica dos Padrões de Homicídio em Alagoas: Maceió e Região Metropolitana.

${ }^{23}$ A PNAD do IBGE é uma pesquisa domiciliar padrão para todo o Brasil, portanto, o indicador é perfeitamente comparável entre os diferentes estados brasileiros, não havendo aqui o tradicional problema nesta área que é a subnotificação dos registros levando-se em conta as diferenças procedimentais entre de registro policial no Brasil. 


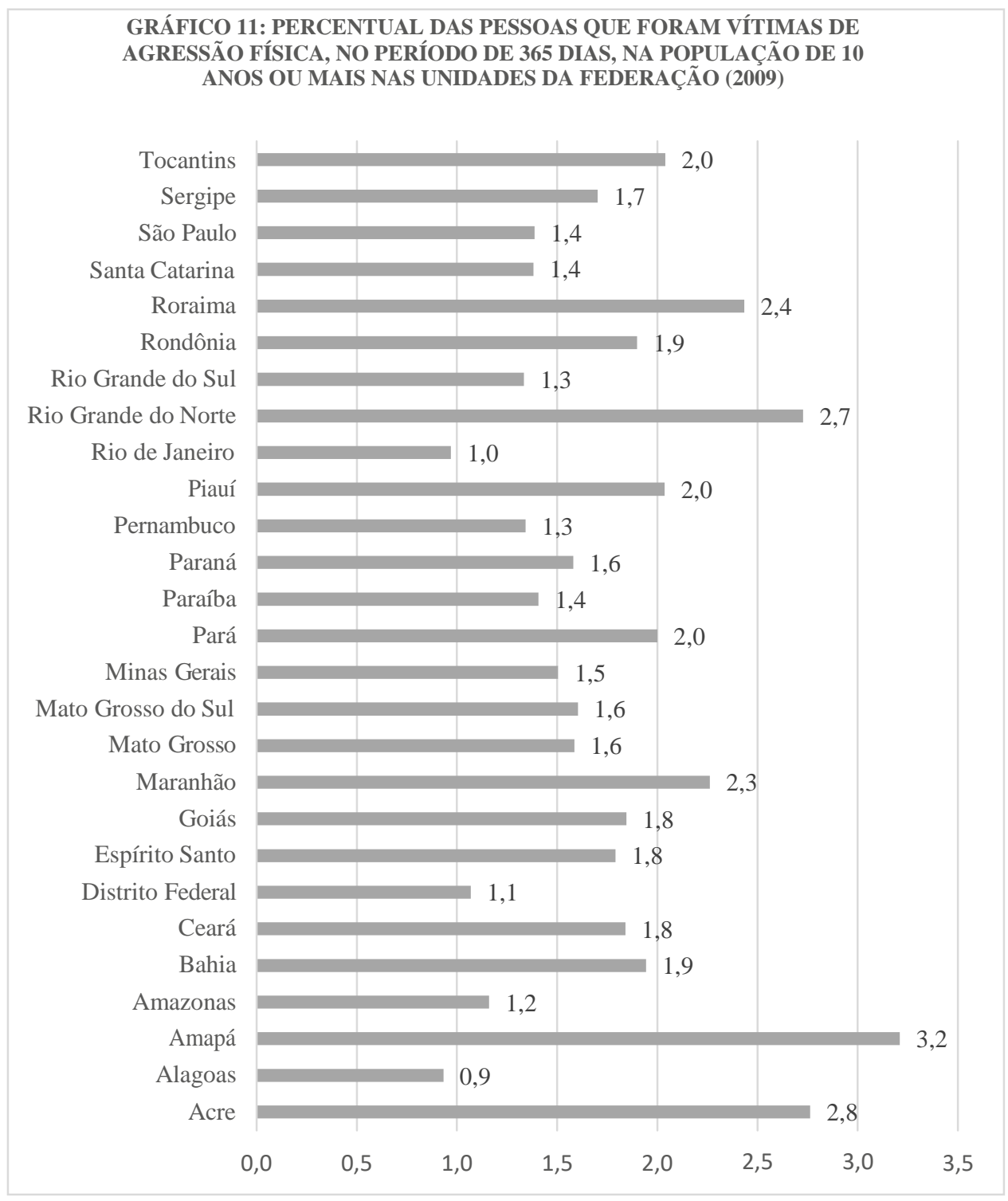

Fonte: IBGE/PNAD

Elaboração dos autores.

Nota: taxa por 100 mil habitantes 
Homicídios em Alagoas: desafios e evidências empíricas

Outro ponto a ser destacado nestes dados é o fato de que pelo menos $56,5 \%$ dessas agressões são cometidas por parentes ou conjugues, ou mesmo por alguém conhecido, das quais, $28 \%$ ocorrem dentro das residências. Estes dados e mais a constatação referente à relativa novidade do crescimento vertiginoso e sistemático dos homicídios no estado (1999) põem em xeque muito do que já fora dito sobre o crime de homicídio no estado, pois mostra que a taxa de letalidade em Alagoas pouco tem a ver com a ideia de um estado intrinsecamente violento ou a predominância de uma cultura violenta de resolução de conflitos entre os alagoanos (ethos). Nesse sentido, também é necessário investir esforços e recursos de pesquisa na verificação de outras hipóteses mais palpáveis na causação do fenômeno como a disseminação de drogas psicoativas e dos mercados ilegais e popularização das armas de fogo, além, é claro, de estudos sobre o ordenamento socioespacial da cidade nas últimas décadas e a efetividade do sistema de justiça criminal no estado ${ }^{24}$.

Em relação aos crimes econômicos, tratando-se mais precisamente de roubos e furtos em Alagoas, o estado também não apresenta uma posição significativa, pois encontra-se respectivamente na $19^{\mathrm{a}}$ e na $24^{\mathrm{a}}$ posição, respectivamente, entre as Unidades da Federação com maior prevalência de roubos e furtos.

Assim, mais uma vez, ressaltamos que do ponto de vista da prevalência, seja de crimes contra o patrimônio, seja de crimes contra a pessoa, o único indicador que faz Alagoas destoar dos demais Estados da Federação é o de violência homicida. Todavia, resta-nos ainda indagar: por que um estado com índices tão altos de violência homicida apresenta percentuais relativamente baixos de roubos e furtos? Uma explicação possível e aceitável seria a baixa retribuição pelo roubo ou furto. Alagoas é o estado com a menor renda domiciliar per capita e com a maior proporção de indivíduos abaixo da linha da pobreza no Brasil o que deve reduzir os incentivos econômicos para perpetrar tais crimes, visto que na maioria das vezes, o ônus da ação pode ser maior que o bônus ${ }^{25}$.

Os dados mostram que não há uma situação congênita de violência no estado de Alagoas. Há sim uma epidemia de homicídios, mas não de agressões físicas, nem de crimes economicamente motivados. $\mathrm{O}$ fato destes percentuais tomarem maior envergadura a partir das duas últimas décadas realçam a necessidade de pesquisas sobre fatores ocorridos nesse período. Com isso não queremos fazer tábula rasa do

${ }^{24}$ Cf. Cerqueira, 2013.

${ }^{25}$ Em breve, com o georeferenciamento dos roubos e furtos cometidos na cidade de Maceió e RM poderemos mapear as áreas de maior vulnerabilidade a roubos e furtos na região, o que, provavelmente, corroborará nossa ideia de que este tipo de crime também tem seu local de influência e ocorrência na cidade. 
acúmulo social dos vários problemas que acometem a população alagoana, mas tão somente enfatizar que considerando-se o comportamento destas taxas ao longo do período, pode-se dizer que os homicídios em Alagoas tendem a se tornar crônicos ${ }^{26}$, impondo desafios às políticas públicas e às ações da sociedade civil. Em outras palavras: sem "explicação", não há "intervenção".

"Explicação" e "intervenção" são temas estreitamente vinculados em segurança pública. A compreensão da dinâmica da estruturação dos grupos em diferentes graus de organização dá-se, principalmente, através da compreensão da forma de organização do espaço urbano, observando-se o desenvolvimento de mecanismos de controle social ou a ausência deles nesses territórios. Nesse sentido, acredita-se que uma melhor compreensão do fenômeno da violência urbana e sua dinâmica de homicídios no espaço urbano de Alagoas facilitarão o desenvolvimento de projetos de intervenção decisivos para o controle destes percentuais.

\section{CONCLUSÃO}

O crime de homicídio em Alagoas tem mostrado um crescimento sistemático, mantendo-se em patamares elevados há mais de duas décadas, sob risco de se apresentar de forma "naturalizada" para a população alagoana. A despeito da crença generalizada de que muito se sabe sobre o problema, na verdade, sabemos pouco e menos ainda sobre as diversas facetas do fenômeno e sobre as próprias políticas públicas de segurança ou das estratégias mais eficazes para driblar o problema e das maneiras mais viáveis de obter resultados a partir da implementação de políticas, programas e projetos palpáveis de segurança pública. Esse tipo de discussão pressupõe uma perspectiva mais empírica e comparativa do fenômeno. Um enfoque menos ensaísta e mais fundamentado em uma robusta base empírica que seja capaz de sustentar diferentes possibilidades de decisão nessa área.

Em linhas gerais, essa dimensão é importante não somente para Alagoas, mas para todo o Brasil, pois muitos projetos de segurança pública aplicados por todo o

${ }^{26}$ Segundo dados do Ministério da Fazenda (MF)/Secretaria do Tesouro Nacional (STN) os valores contabilizados para despesas realizadas em 2012 com a função Segurança Pública/Informação e Inteligência foram de $\mathrm{R} \$ 5.903 .983,42$, apresentando portanto uma variação de $\mathrm{R} \$ 2.232,50 \%$, tendo em vista que para o ano de 2011 foram contabilizados somente $\mathrm{R} \$ 253.118,20$. A ampliação dos gastos com informação e inteligência para o estado de Alagoas são positivos, todavia, quando comparado para com as despesas referentes a Policiamento no mesmo ano R \$ 515.911.480,33, percebe-se que a inciativa ainda é tímida, levando em conta a escala do fenômeno da violência homicida.

Latitude, Vol. 7, nº 2, pp. 109-132, 2013 
Homicídios em Alagoas: desafios e evidências empíricas

território nacional têm se pautado mais por fortes pressupostos de conteúdo impressionístico, político ou ideológico e menos pela racionalização do fenômeno e por políticas preventivas. É necessário que as discussões que orientam a ação de Estado e gestão sejam amparadas por forte base teórica e conceitual para dar-lhes sustentação, por isso mesmo, necessitamos também investir em um enfoque mais pragmático que possa oferecer um conhecimento sólido e aplicável e base empírica para generalizações que possam subsidiar pesquisadores e policymakers.

Uma das dimensões cruciais para o sucesso de políticas públicas de segurança é a disponibilidade de ferramentas de avaliação e monitoramento, bem como de diagnósticos abrangentes e úteis para fins de planejamento e implementação de programas e projetos de segurança pública. No que compreende a experiência brasileira, os investimentos tímidos no desenvolvimento de tais ferramentas têm raízes na própria forma como se desenvolveu entre nós os estudos sobre criminalidade. Não temos no Brasil ainda cursos de criminologia ao nível de graduação e a oferta de mestrados nessa área ainda é bastante limitada, isso estimulou que a criminologia, ora fosse restrita à perspectiva do direito penal ou direito processual penal, ora fosse vista como reduto exclusivo dos sociólogos e antropólogos. Não obstante, a criminologia é espaço de todos e de nenhum em primazia.

\section{BIBLIOGRAFIA}

BACHA, E. L. \& SCHWARTZMAN, S. Org. (2011). Brasil: A Nova Agenda Social. Rio de Janeiro: LTC.

BEATO, C. (2008). Compreendendo e Avaliando Projetos de Segurança Pública. Minas Gerais: Editora UFMG.

BEATO, C. (2012). Crime e Cidades. Belo Horizonte, Editora da UFMG.

BORGES, Dorian et al. 2013. “Mortes Violentas no Brasil: Uma Análise do Fluxo de Informações", In: FIGUEIREDO, Isabel Seixas de \& NEME, Cristina; LIRA, Cristiane do Socorro Loureiro. Homicídios no Brasil: Registro e Fluxo de Informações. Brasília: Ministério da Justiça, Secretaria Nacional de Segurança Pública (SENASP), (Coleção Pensando a Segurança Pública, vol. 01).

MANSO, B. P. (2012). Crescimento e Queda dos Homicídios em SP entre 1960 e 2010. Uma análise dos mecanismos da escolha homicida e das carreiras do crime. $304 \mathrm{f}$. Tese (Doutorado em Ciência Política) - Faculdade de Filosofia, Letras e Ciências Humanas, São Paulo. 
Emerson do Nascimento; Júlio Cezar Gaudêncio

CERQUEIRA, D. R. C. (2010). Causas e Consequências do Crime no Brasil. 168 f. Tese (Doutorado em Economia) - Departamento de Economia, Pontifícia Universidade Católica do Rio de Janeiro, Rio de Janeiro.

CRUZ, M.V., BATITUCCI, E., Orgs. (2007). Homicídios no Brasil. Rio, Editora FGV.

EISNER, M. (2009). The uses of violence: An examination of some cross-cutting issues. International Journal of Conflict and Violence, 3, 40-59.

ELIAS, Nobert. (2011a). O Processo Civilizador. Volume 1: Uma História dos Costumes. Rio de Janeiro: Zahar Editor.

ELIAS, Nobert. (2011b). O Processo Civilizador. Volume 2: Formação do Estado e Civilização. Rio de Janeiro: Zahar Editor.

EISNER, Manuel. (2001). Modernization, Self-control and Lethal Violence: The Longtem Dynamics of European Homicide Rates in Theoretical Perspective. Britsh Journal of Criminology, no 41, p. 618-638.

FÓRUM BRASILEIRO DE SEGURANÇA PÚBLICA. Anuário Brasileiro de Segurança Pública 2012. Disponível em: http://www2.forumseguranca.org.br/

FOUCAULT, Michel. (2006). Vigiar e Punir - Nascimento da Prisão. Petrópolis: Vozes.

FREITAS, W. C. P. (2002). Espaço Urbano e Criminalidade: Lições da Escola de Chicago. São Paulo: IBCCRIM.

LIEM, M. \& PRIDEMORE, W. (2012). Handbook of European Homicide Research. Patterns, Explanations and Country Studies. Springer.

MESSNER, S.F. \& ROSENFELD, R. (1997). Political restraint of the Market and levels of criminal homicide: a cross-national application of institutional-anomie theory. Social Forces, 7, 1393-1416.

MINISTÉRIO DA SAÚDE.DATASUS. http://www2.datasus.gov.br/DATASUS/index.php

MISSE, M. (2006). Crime e violência no Brasil contemporâneo. Rio, Lumen Juris.

MONKKONEN, E. (2006). Homicide: Explaining America's exceptionalism. American

Historical Review, 111 (1): 76-94.

SECRETARIA DE SÁUDE DO ESTADO DE ALAGOAS. http://www.saude.al.gov.br/ SOARES, G.A.D. (2008). Não matarás. Desenvolvimento, desigualdade e homicídios. Rio de Janeiro, Editora FGV.

SPIERENBURG, Pieter. Long-term trends in Homicide: theoretical reflections and Dutch evidence, fifteenth to twentieth century. In: JOHNSON, E. A.; MONKKONEN, E. J. (1996). The Civilization of Crime: Violence in Town $\mathcal{E}$ Country Since the Middle Ages. Urbana: University of Illionois Press.

Latitude, Vol. 7, nº 2, pp. 109-132, 2013

DOI: https://doi.org/10.28998/2179-5428.20130207 
Homicídios em Alagoas: desafios e evidências empíricas

VASCONCELOS, R. \& PIMENTEL, E. (2011). As faces da segurança pública e dos direitos humanos em Alagoas. Maceió, EDUFAL.

VASCONCELOS, R. \& PIMENTEL, E. (2009). Violência e Criminalidade em Mosaico. Maceió, EDUFAL.

VERKKO, V. (1951). Homicides and suicides in Finland and their dependence on national character. Copenhagen: G.F.C. Gads Forlag.

WAISELFISZ, J. J. (2012). Mapa da Violência 2012. Os novos padrões da violência homicida no Brasil. São Paulo, Instituto Sangari. http://www.mapadaviolencia.org.br/

WOLFGANG, M. (1958). Patterns of criminal homicide. Philadelphia, University of Pennsylvania Press.

ZALUAR, A. (1994). Condomínio do Diabo. Rio de Janeiro, Editora UFRJ.

ZANOTELLI, C. (2003). Desterritorialização da Violência no Capitalismo Globalitário: o caso do Brasil e do Espírito Santo. Revista Terra Livre, São Paulo, v. 2, n. 21, p. 225-240. WEBER, Max. (1981). Metodologia das Ciências Sociais. São Paulo: Cortez. 